profession needs something more than a "forum for discussion" in its Central Council for Postgraduate Education if the practice of medicine is to be kept up to the standards the country must have.

\section{Cause for Concern}

In July 1967 a 7-year-old boy was admitted to Paddington General Hospital with a provisional diagnosis of appendicitis or mesenteric adenitis, and his appendix was removed during the night. The next day, a Saturday, he became feverish and delirious, and he died early on Sunday morning. Necropsy showed the cause of death to be an overwhelming virus infection. The child's parents were naturally greatly distressed by this sudden death and made some criticisms of his management at the hospital.

Several informal inquiries were made into the death, but eventually in January 1969 a committee was set up by the Secretary of State for Health and Social Services to inquire into the organization of medical and nursing care of children at the hospital with particular reference to the case of the dead child. The committee reported its findings to the Health Department in April of this year. Last week two national newspapers printed accounts of the committee's findings, and the same day the full text ${ }^{1}$ of the report was released ${ }^{2}$ to the press.

The report states that it was most unlikely that anything could have been done to prevent the child's death, but it made several criticisms about the management of the case. The hospital had 469 beds, 20 in the children's ward. Three preregistration surgical house officers were resident at the hospital, but the surgical registrars lived out, as did the paediatric registrar. At weekends, therefore, the hospital was left to the care of preregistration doctors, and the house surgeon on duty had about 100 patients to look after. There should have been 357 nurses at the hospital ; in fact there were only 257 , and on the weekend in question the children's ward had neither a sister nor a staff-nurse on duty.

The main medical recommendation made by the report is that children admitted to hospital for any reason should come under the care of specialist paediatricians. No one will quarrel with this conclusion, but, as in so many branches of medicine, expert attention 24 hours a day can be provided only by setting up large units with large catchment areaswhich means that patients and relatives may have to travel far from home. Small paediatric units of the kind at Paddington will disappear as the large district general hospitals are introduced.

Two disturbing situations, however, have been highlighted by publication of the report. Firstly, in a large hospital responsibility for the day-to-day care of patients was left to student nurses and preregistration doctors. Both are supposed to be in training, yet the report showed that both were overworked and given too little support at Paddington General Hospital. It is hardly surprising that there were delays in recognizing a serious illness and seeking experienced advice.

The second disturbing feature is the number and nature of the inquiries held into the child's death. The Secretary of

\footnotetext{
1 Department of Health and Social Security. Medical and Nursing Care of Children at Paddington General Hospital : Report of Committee of Inquiry, April 1969.

The Times, 9 December 1969.
}

B
State for Health and Social Services is given very wide powers to hold inquiries under the $1946 \mathrm{Act}^{3}$ and it is right that he should be able to investigate defects in the service for which he bears responsibility. When matters of clinical responsibility and professional competence are concerned, however, it is questionable whether an administrative investigation is the right solution. A doctor whose clinical judgement has been at fault may expect censure from his colleagues and perhaps an action for negligence in the courts; but he should not be exposed in addition to the judgement of a body, not bound by precedent, whose findings are not subject to appeal. Furthermore, as this case has shown, a private inquiry within the N.H.S. may fail to satisfy aggrieved parents. Informal investigation and explanation often satisfy the understandable anxieties of relatives; but if such informal procedures fail there is no satisfactory substitute for the open process of the courts when professional competence is in question.

\section{Phenacetin and Bladder Cancer}

Ever since L. Rehn ${ }^{1}$ commented on what seemed to be an undue incidence of bladder cancer among workers making the aniline dye fuchsin there has been intense interest in the relationship between chemicals and bladder cancer. By 1938 it was shown that not aniline itself, but a derivative-betanaphthylamine-could cause bladder tumours in animals. Since then more carcinogens having this action have been identified $^{2}$ and more industries have been shown to carry this risk. Among them are industries concerned with rubber, cable-covering, dyestuffs, pitch and tar, printing, and dyeing. Laboratory workers must guard against it, and even rat catchers must take precautions. ${ }^{3-6}$

But by no means all those who get cancer of the bladder work in these industries. Perhaps some work in trades where a carcinogen exists but has not been identified owing to the long latent interval which may elapse between exposure to the carcinogen and development of the cancer. With the well-known carcinogen beta-naphthylamine the mean interval between exposure and disease is about 17 years, and some cases go as long as 40 years before the cancer appears. ${ }^{7}$

In other cases it seems very unlikely that any industrial carcinogen can be at fault. Of such patients it is claimed that some $50 \%$ excrete in the urine abnormally large amounts of various substances derived from the metabolism of tryptophan. $^{8} \quad$ It was suggested that these tryptophan derivatives might appear in the urine in consequence of some inherited

Rehn,.L., Archiv für Klinische Chirurgie, 1895, 50, 588.

Boyland, E., The Biochemistry of Bladder Cancer, 1963. Springfield Illinois, Thomas.

3 Case, R. A. M., and Hosker, M. E., British fournal of Preventive and Social Medicine, $1954,8,39$.

- Davies, J. M., Lancet, 1965, 2, 143.

5 Case, R. A. M., Annals of the Royal College of Surgeons of Englani,

- Wallace, D., American fournal of Roentgenology, Radium Therapy and Nuclear Medicine, 1968, 102, 581.

7 Veys, C. A., Urologia Internationalis, 1969, 24, 276.

8 Bryan, G. T., American Industrial Hygiene Association fournal, 1969, 30, 27.

- Fraumeni, J. F., jun., Fournal of the National Cancer Institute, 196s, 41, 1205 10 Angervall, L., Bengtsson, U., Zetterlund, C. G., and Zsigmond, M.,

11 Bengtsson, U., Angervall, L., Ekman, H., and Lehmann, L., Scandi navian fournal of Urology and Nephrology, 1968, 2, 145.

12 Clayson, D. B., Lawson, T. A., and Pringle, J. A. S., British fourna? of Cancer, 1967, 21, 755 . 
defect, pussibly through the lack of some protective enzyme. It has also been suggested that smoking, which statistically is as closely related to deaths from bladder cancer as it is to deaths from lung cancer, ${ }^{9}$ may effect its carcinogenic action through the intermediary of an alteration in tryptophan metabolism.

What, if anything, have the tryptophan metabolites in common with the identified industrial carcinogens ? Essentially, it seems that they share a common basic structure of an amine group linked to a benzene ring-they are aminophenols. But so are a great many supposedly innocuous substances, including many licit additives and dyestuffs in food as well as drugs in everyday use such as phenacetin, which is excreted largely as a para-aminophenol. ${ }^{11}$

Recently disturbing reports have been published that phenacetin abuse may not only give rise to nephropathy and necrosis of the renal papillae but also to cancer of the cells lining the renal pelvis. ${ }^{10} 11$ The most recent study comes from a small hospital in south Sweden serving the little town of Huskvarna. Here the main industry is a small-arms factory, where, ever since the influenza epidemic of 1918, it has been a habit for the people to take relatively large quantities of "Hjorton's powder," which contains phenacetin, phenazone, and caffeine. Cf the 15 patients in their hospital who had urothelial cancer of the renal pelvis ten were Huskvarna phenacetin takers and all but two had phenacetin nephropathy and renal papillary necrosis. ${ }^{11}$

Why the carcinoma arose in the urothelium of the kidney rather than in the more usual place, the urothelium of the bladder, is a question which is of considerable theoretical interest. Carcinogenesis from chemicals in the urinary tract seems to demand two things-initiation and development or cocarcinogenesis. Hyperplasia in response to irritation of many different types, from stones to paraffin wax pellets, seems to speed the development of carcinoma. ${ }^{12}$ The fact that the phenacetin produced scarring, calcification, and papillary necrosis, and so presumably irritation in the renal pelvis, may be the reason why cancer appeared there before the bladder. Unfortunately we do not know how many of the Huskvarna victims also smoked.

\section{Wigs and Waste}

A proposed increase in patients' payments for teeth and spectacles can threaten a political crisis, but the cost of N.H.S. wigs has provoked little comment since the early days of the Health Service. This is surprising, for their initial cost and maintenance may amount to a charge of over $£ 1 \mathrm{~m}$. a year on the taxpayer. Figures obtained by the B.M.A. Dermatologists Group showed that the average annual cost in the period 1965-7 for two regional hospitals serving populations of 300,000 and 100,000 was $£ 6,778$ and $£ 2,432$ respectively.

Patients are usually supplied with two wigs, which cost about $£ 33$ each. Partial transformations cost somewhat less, but they are prescribed infrequently. An accompanying leaflet, Taking Care of Your Wig, states that one of the two wigs should be cleaned and dressed every month. Each service costs 18s., and thus the cost of maintenance may amount to about half of the total cost of new wigs supplied. Some hospital groups are spending over $£ 2,000$ a year on the cleaning and maintenance of wigs.
The main reason why the expenditure on wigs is so heavy is the large number of elderly women with thinning hair (involutional alopecia) who are referred to dermatologists in the belief that free wigs are their right. These patients are not eligible for wigs if the regulations are strictly interpreted. Wigs may be provided under the N.H.S. only for baldness due to congenital dystrophy of the skin; alopecia totalis ; alopecia areata, severe and long standing; extensive scarring following trauma, $x$-irradiation, or an inflammatory condition; or in cases of illness or treatment of illness where baldness, though not permanent, is likely to be prolonged. The wig must be considered necessary by a consultant.

In practice it is difficult for a dermatologist to refuse a wig to a distraught grandmother with an incipient male-type tonsure who has been told that she can obtain a wig from the hospital free of charge. But unless the prescribing of wigs is restricted to the conditions specified in the regulations they will continue to be supplied in ever increasing numbers as our aged population grows. Costs could be reduced substantially if the consultant could at his discretion order a cheaper wig-a nylon-acrilan one costs little over $£ 3$-instead of the standard, expensive one.

One of the faults of a free health service is that the easy way out of a difficult situation is often the most expensive one. A nation which spends $£ 1 \mathrm{~m}$. a year on wigs has got its priorities wrong.

\section{Neurological Sequelae of Partial Gastrectomy}

Though partial gastrectomy has been blamed for a long list of troubles, the risks of their developing are often considered acceptable. Postprandial disturbances are usually an improvement on the pain that the patient experienced before his operation, and symptoms that may develop later owing to deficiency states are as a rule at least partially responsive to replacement therapy. But some sequelae occur so rarely and so long after partial gastrectomy that the significance of the operation is easily overlooked. Certain neurological disturbances come into this category.

In Birmingham a special interest has been taken in the complications and metabolic consequences of partial gastrectomy. ${ }^{1}$ J. A. Williams and his colleagues ${ }^{2}$ have recently extended this experience to an analysis of neurological disease, occasionally occurring many years after partial gastrectomy.

Reports have appeared in the past of subacute combined degeneration of the cord many years after partial gastrectomy. ${ }^{34}$ Wider recognition has been given in Scandinavia to "myelopathy" associated with low serum levels of vitamin $B_{12}$ after this operation. ${ }^{5}$ Patients with low

1 Stammers, F. A. R., and Williams, J. A. (eds.), Partial Gastrectomy, Complications and Metabolic Consequences, 1963. London, Butterworths.

${ }^{2}$ Williams, I A. Hall, G. S. Thompson, A. G., and Cooke, W. T., British Medical fournal, 1969, 3, 210.

3 Knox, J. D. E., and Delamore, I. W., British Medical fournal, 1960, 2,1494 .

4 Weir, D. G., and Gatenby, P. B. B., British Medical fournal, 1963, 2,

5 Olivarius, B. de F., and Roos, D., Lancet, 1965, 2, 1298.

6 Witts, L. J., The Stomach and Anaemia, 1966. London, Athlone Press. Deller, D. J., Australasian Annals of Medicine, 1962, 2, 235.

8 Cooke, W. T., Johnson, A. G., and Woolf, A. L., Brain, 1966, 89, 663. 9 Cooke, W. T., and Smith, W. T., Brain, 1966, 89, 683. 